\title{
Características físico-químicas da carcaça e da carne de novilhas submetidas ao anestro cirúrgico ou mecânico terminadas em confinamento ${ }^{1}$
}

\author{
Jair de Araújo Marques 2 , Ivanor Nunes do Prado ${ }^{3}$, José Luiz Moletta ${ }^{4}$, Ivor Martin do Prado ${ }^{5}$, Juliana \\ Martin do Prado ${ }^{5}$, Lívia Maria Araújo Macedo ${ }^{6}$, Nilson Evelázio de Souza ${ }^{7}$, Makoto Matsushita ${ }^{7}$ \\ ${ }^{1}$ Parte da tese do primeiro autor - Programa de Pós-Graduação em Zootecnia (PPZ) da Universidade Estadual de Maringá (UEM). \\ 2 Integrado Colégio e Faculdade Campo Mourão - PR. Convênio EMATER/IAPAR. \\ ${ }^{3}$ Departamento de Zootecnia da Universidade Estadual de Maringá - Av. Colombo, 5790 - CEP: 87020-900 Maringá-PR. Bolsista \\ Produtividade I - CNPq. \\ ${ }^{4}$ IAPAR. \\ ${ }^{5}$ Curso de Engenharia de Alimentos da UEM. Bolsista CNPq. \\ ${ }^{6}$ Bolsista de Aperfeiçoamento Técnico - CNPq. \\ ${ }^{7}$ Departamento de Química da UEM. Bolsista em produtividade em pesquisa-CNPq.
}

RESUMO - Objetivou-se com este trabalho avaliar o efeito da simulação da prenhez (introdução de 100 esferas de chumbo no útero - CHU) e da ovariectomia (retirada dos ovários - OVA) sobre as características físico-químicas da carcaça e da carne de novilhas. Foram utilizadas 19 novilhas mestiças ( $1 / 2$ Nelore x $1 / 2$ Red Angus), com 18 meses de idade e peso médio inicial de $257,8 \mathrm{~kg}$, terminadas em confinamento recebendo uma dieta à base de silagem de milho (41\%) e farelo de soja e milho (59\%). O peso vivo ao abate, sem diferença entre tratamentos, foi de 324,1; 323,3 e 303,0 kg para as novilhas dos tratamentos VAZ, CHU e OVA, respectivamente. Da mesma forma, não houve diferença entre tratamentos para peso de carcaça quente $(171,1 \mathrm{~kg})$, comprimento de carcaça $(113,8 \mathrm{~cm})$, comprimento de perna $(68,2 \mathrm{~cm})$, espessura do coxão $(21,0 \mathrm{~cm})$, área de olho-de-lombo $\left(57,3 \mathrm{~cm}^{2}\right)$, espessura de gordura de cobertura $(4,0 \mathrm{~mm})$, proporções de músculo $(62,6 \%)$, osso (16,0\%) e gordura $(21,7 \%)$, relação músculo/osso $(3,9)$, relação músculo + gordura (porção comestível)/osso $(5,3)$, perdas por cocção $(24,3 \%)$, perdas do congelamento à cocção $(30,9 \%)$, maciez $(7,1$ pontos), suculência ( 6,6 pontos) e palatabilidade ( 6,6 pontos). Os parâmetros cor, textura e marmoreio também não diferiram entre os tratamentos, apresentando, respectivamente, 4,0; 4,4 e 3,7 pontos. Não houve diferença significativa para os teores de cinzas $(1,1 \%)$ e PB $(21,8 \%)$ e para as concentrações de extrato etéreo total $(2,9 \%)$ e colesterol $(49,6 \mathrm{mg} / 100 \mathrm{~g})$ do músculo Longissimus dorsi. Portanto, a ocorrência do estro não alterou as características analisadas.

Palavras-chave: carcaça, composição física, proteína bruta, suculência, umidade

\section{Carcass and meat traits of feedlot finished heifers submitted to surgical or mechanical anoestrous}

\begin{abstract}
This study was conducted to evaluate the effect of pregnancy simulation (placement of 100 lead spheres in the uterus-LEAD) and ovariectomy (OVAE) on traits of carcass and meat of heifers finished in feedlot. Animals not pregnant and with intact ovary were used as the control (CTRL). Nineteen crossbred heifers ( $1 / 2$ Nelore x $1 / 2$ Red Angus) averaging 18 months of age and $257.8 \mathrm{~kg}$ of body weight were used. Animals were fed a diet containing (\% DM): $41 \%$ of corn silage and $59 \%$ of soybean meal, corn, and trace minerals. No significant differences were observed for slaughter weight, which averaged $324.1,323.3$, and $303.3 \mathrm{~kg}$, respectively, for CTRL, LEAD, and OVAE treatments. Similarly, there were no significant differences among treatments for the following variables: hot carcass weight $(171.1 \mathrm{~kg})$, carcass length $(113.8 \mathrm{~cm})$, hind limb length $(68.2 \mathrm{~cm})$, cushion thickness $(21.0 \mathrm{~cm})$, loin eye area $\left(57.3 \mathrm{~cm}^{2}\right)$, fat thickness $(4.0 \mathrm{~mm})$, percentages of muscle $(62.6 \%)$, bone (16.0\%), and fat (21.7\%), muscle/fat ratio (3.9), muscle plus fat/bone ratio (5.3), cooking losses $(24.3 \%)$, freezing to cooking losses (30.9\%), tenderness (7.1 points), juiciness (6.6 points), and flavor (6.6 points) The color, texture, and marbling parameters also did not differ averaging 4.0, 4.4, and 3.7 points, respectively, among treatments. In addition, no significant differences were found to contents of ash $(1.1 \%)$, crude protein $(21.8 \%)$, total fat $(2.9 \%)$, and cholesterol $(49.6 \mathrm{mg} / 100 \mathrm{~g})$ in the Longissimus dorsi muscle. Thus, it can be concluded that estrus did not affect carcass characteristics.
\end{abstract}

Key Words: carcass, crude protein, moisture, physical composition, tenderness 


\section{Introdução}

Conforme o ANUALPEC (2003), o comércio de carne deve apresentar grande crescimento neste milênio. Com este crescimento, ocorrerão mudanças nos sistemas de criação e produção, nas pesquisas, nas políticas governamentais e de marketing e, mais intensamente, no comportamento do consumidor (escolha de produtos de melhor qualidade e mais baixo risco à saúde humana).

De modo geral, as características físicas da carcaça podem ser manipuladas por meio do manejo nutricional (Marques et al., 2000), da idade de abate (Restle et al., 1999), da escolha do sistema de produção e de raças para produção de carne (Moletta \& Restle, 1996), entre outros fatores.

Segundo Restle et al. (1999), a terminação de animais mais jovens é mais eficiente que a de animais em idade mais elevada; desse modo, os mais jovens poderiam ser comercializados sem prejuízos para o consumidor. No entanto, estas carcaças devem apresentar espessura de gordura de cobertura de 3 a $6 \mathrm{~mm}$.

A carne bovina, um alimento altamente protéico, é uma das principais fontes de nutrientes para o homem, sendo classificada como um alimento completo e de alto valor biológico, por apresentar todos os aminoácidos essenciais nas proporções corretas (Pensel, 1998). Além disso, é rica em vitaminas, sobretudo do complexo $\mathrm{B}$, e minerais, especialmente ferro, que apresenta funções biológicas importantes no organismo (Bobbio \& Bobbio, 1995), em razão da maior proporção de fibras musculares (Costa et al., 2002).

Entretanto, o consumo de carne, principalmente bovina (vermelha), tem sido vinculado a problemas de saúde como excesso de peso, arteriosclerose, tumores malignos e hipertensão, provavelmente em virtude da presença de gordura saturada e colesterol. Todavia, Jiménez-Colmenero et al. (2001) observaram, em análise química da carne bovina, teores de gordura na porção muscular inferiores a $5 \%$, representando, aproximadamente, um terço das necessidades diárias de colesterol de um indivíduo adulto (Moreira et al., 2003).

Um fator negativo que interfere no desempenho e na produção de carne de novilhas é o aparecimento de estros a cada 21 dias (Prado et al., 2000), provocando alterações na coloração e maciez da carne (Crowe et al., 1995).

O objetivo neste trabalho foi avaliar o efeito do anestro, mecânico ou cirúrgico, sobre as características físicoquímicas da carcaça e da carne de novilhas terminadas em confinamento.

\section{Material e Métodos}

O experimento foi conduzido no Setor de Bovinocultura de Corte da Fazenda Experimental de Iguatemi e as análises foram realizadas no Laboratório de Alimentos do Departamento de Química da Universidade Estadual de Maringá (UEM).

Utilizaram-se 19 novilhas mestiças $(1 / 2$ Nelore $\mathrm{x} 1 / 2$ Red Angus) com 18 meses de idade e peso médio inicial de $257,8 \mathrm{~kg}$ terminadas em confinamento. Foram estudados três tratamentos: VAZ - sete novilhas com atividade ovariana (ciclo estral), porém, vazias; $\mathrm{CHU}$ - sete novilhas com 100 esferas $(4,0 \mathrm{~mm}$ de diâmetro) de chumbo introduzidas nos cornos uterinos; OVA - cinco novilhas ovariectomizadas (remoção dos ovários). A introdução das esferas de chumbo foi feita utilizando-se pipeta de inseminação e a ovariectomização, por meio de cirurgia. Após período de 21 dias de adaptação às instalações e recuperação dos procedimentos (tratamentos), os animais foram confinados por 63 dias. O peso vivo médio ao abate, após jejum de 12 horas, foi de 324,1;323,3 e 303,0 kg para as novilhas dos tratamentos VAZ, CHU e OVA, respectivamente.

Durante o período de confinamento, as novilhas foram alojadas em baias individuais com piso de concreto, parcialmente cobertas, e com livre acesso aos comedouros e bebedouros. Os animais foram alimentadas à vontade com uma dieta contendo silagem de milho, farelo de soja, milho e sal mineral na proporção volumoso:concentrado 41:59, com base na matéria seca (Tabela 1).

Após o abate, as carcaças foram identificadas, pesadas e mantidas em câmara de resfriamento a $4,0^{\circ} \mathrm{C}$ durante 24 horas. Após o resfriamento, a meia-carcaça direita foi avaliada quanto às características quantitativas, ou seja, comprimentos de carcaça e de perna, espessuras do coxão e da gordura de cobertura, proporções de osso, músculo e gordura, cor, textura, marmoreio, perdas por descongelamento e cocção, maciez, suculência e palatabilidade.

As características da carcaça e da carne foram avaliadas de acordo com metodologia descrita por Muller (1980), enquanto as porcentagens de músculo (PM), osso (PO) e gordura (PG) da carcaça foram determinadas pela metodologia descrita por Hankins \& Howe (1946), adaptadas por Müller et al. (1973), citados por Moletta \& Restle (1996).

Amostras da meia-carcaça direita foram moídas e analisadas para determinação dos teores de MS, CIN, PB e EE total, segundo metodologia descrita pela AOAC (1980). A 
Tabela 1 - Composições química e percentual (\%/MS) das dietas experimentais Table 1 - Chemical and ingredient compositions of the experimental diet, DM basis

$\%$ MS $(\% D M)$

\begin{tabular}{|c|c|c|c|c|c|c|c|c|}
\hline $\begin{array}{l}\text { Ingrediente* } \\
\text { Ingredient* }\end{array}$ & $\begin{array}{l}\text { MS } \\
D M\end{array}$ & $\begin{array}{l}\mathrm{PB} \\
C P\end{array}$ & $\begin{array}{l}\mathrm{MO} \\
O M\end{array}$ & $\begin{array}{l}\mathrm{MM} \\
A S H\end{array}$ & $\begin{array}{c}\mathrm{EB} \# \\
G E\end{array}$ & $\begin{array}{l}\text { FDN } \\
N D F\end{array}$ & $\begin{array}{l}\mathrm{FDA} \\
A D F\end{array}$ & $\begin{array}{c}\text { Ração (\%) } \\
\text { Diet (\%) }\end{array}$ \\
\hline $\begin{array}{l}\text { Silagem de milho } \\
\text { Corn silage }\end{array}$ & 31,7 & 5,9 & 94,8 & 5,2 & 4,3 & 64,9 & 36,5 & 41,0 \\
\hline $\begin{array}{l}\text { Milho } \\
\text { Corn }\end{array}$ & 88,6 & 10,8 & 98,7 & 1,3 & 4,3 & 12,1 & 4,1 & 47,2 \\
\hline $\begin{array}{l}\text { Farelo de soja } \\
\text { Soybean meal }\end{array}$ & 88,6 & 51,4 & 93,7 & 6,3 & 4,7 & 15,7 & 10,1 & 11,8 \\
\hline $\begin{array}{l}\text { Ração } \\
\text { Diet }\end{array}$ & 65,2 & 13,6 & 96,5 & 3,5 & 4,3 & 34,2 & 18,1 & \\
\hline
\end{tabular}

* Dados obtidos no Laboratório de Análises de Alimentos, Alimentação e Nutrição Animal - DZO/UEM.

\#Megacalorias $/ \mathrm{kg}^{1} \mathrm{~g} / \mathrm{animal} / \mathrm{dia}$.

* Data obtained from Feed Analyses Laboratory and Animal Nutrition - DZO/UEM.

\# Megacalories $/ \mathrm{kg}^{1} \mathrm{~g} / \mathrm{an} / \mathrm{day}$.

extração do colesterol foi feita segundo método reportado por Al-Hasani et al. (1993).

O delineamento experimental foi inteiramente casualizado, com três tratamentos e sete repetições para os tratamentos VAZ e CHU e cinco repetições para o tratamento OVA. Os dados de peso de carcaça, em kg e em arrobas, de rendimentos de carcaça, de comprimentos de carcaça e de perna, espessuras do coxão e da gordura, proporções de osso, músculo e gordura, cor, textura, marmoreio, perdas por descongelamento e cocção, maciez, suculência e palatabilidade, bem como das características químicas da carne, foram submetidos à análise de variância e as médias comparadas pelo teste Tukey a 5,0\% de significância, utilizando-se o SAEG (1997), conforme modelo descrito abaixo.

$$
\mathrm{Y}_{\mathrm{ij}}=\mu+\mathrm{t}_{\mathrm{i}}+\mathrm{e}_{\mathrm{ij}}
$$

em que: $Y_{i j}=$ observação no animal $j$ submetido ao tratamento $\mathrm{i} ; \mu=$ constante geral $; \mathrm{t}_{\mathrm{i}}=$ efeito do tratamento $\mathrm{i} ; \mathrm{i}=1 ; \ldots ; 3$; e $e_{i j}=$ erro aleatório associado a cada observação $Y_{i j}$.

\section{Resultados e Discussão}

$\mathrm{Na}$ Tabela 2 são apresentados os valores referentes ao peso vivo ao abate (PVA), em $\mathrm{kg}$, ao peso de carcaça quente (PCQ), em kg, e ao peso de carcaça, em arroba (PAR), os quais não diferiram entre os tratamentos (médias de 316,$8 ; 171,1$ e 11,4 ; respectivamente), provavelmente em razão da expulsão das esferas de chumbo do interior do útero das novilhas do tratamento $\mathrm{CHU}$, prejudicando seu efeito sobre estes parâmetros, pois, ao abate não foi observada a presença das esferas no interior do útero das novilhas.
Tabela 2 - Peso vivo ao abate (PVA), peso de carcaça quente (PCQ) e peso de carcaça em arrobas (PAR) de novilhas mestiças submetidas ao anestro mecânico (CHU) ou cirúrgico (OVA), comparadas a novilhas controle (VAZ), terminadas em confinamento

Table 2 - Slaughter body weight (SBW), wet carcass weight (WCW) and arroba carcass weight (ACW) of heifers submitted to mechanical (LEAD) or surgical anoestrous (OVAE) compared to control (CTRL)

\begin{tabular}{lccccc}
\hline $\begin{array}{l}\text { Parâmetros } \\
\text { Item }\end{array}$ & $\begin{array}{c}\text { VAZ } \\
\text { CTRL }\end{array}$ & $\begin{array}{c}\text { CHU } \\
\text { LEAD }\end{array}$ & $\begin{array}{c}\text { OVA } \\
\text { OVAE }\end{array}$ & $\begin{array}{c}\text { Média } \\
\text { Mean }\end{array}$ & CV (\%)* \\
\hline $\begin{array}{l}\text { PVA, kg } \\
\text { SBW, kg }\end{array}$ & 324,1 & 323,3 & 303,0 & 316,8 & 9,1 \\
$\begin{array}{l}\text { PCQ, kg } \\
\text { WCW, kg }\end{array}$ & 174,2 & 175,1 & 164,0 & 171,1 & 8,8 \\
PAR, @ & 11,6 & 11,7 & 10,9 & 11,4 & 8,8 \\
$A C W, @$ & & & & & \\
\hline
\end{tabular}

${ }^{*}$ Coeficiente de variação (Coefficient variation).

Kutsunugi (2004) não observou variação nos níveis de progesterona nos animais do tratamento $\mathrm{CHU}\left(\mathrm{P}_{4}=\right.$ $0,9 \mathrm{ng} / \mathrm{mL}$ ), tanto para o início quanto para o final do experimento. Entretanto, os animais não apresentaram sinais de cio neste tratamento. Por outro lado, o que pode dar informações definitivas sobre o ciclo estral dos animais dos tratamentos CHU e VAZ são as avaliações histológicas dos ovários.

O PVA foi inferior ao encontrado por Marques et al. (2001), que, em estudo com novilhas mestiças ( $1 / 2$ Nelores $\mathrm{X}$ $1 / 2$ Angus) de idade semelhante (20 meses) durante 56 dias de confinamento, avaliaram a influência dos hormônios da reprodução e observaram PVA de 350,9 kg. Da mesma forma, Marques et al. (2000), em novilhas mestiças ( $1 / 2$ Nelore $x 1 / 2$ Angus ou 1/2 Nelore x 1/2 Simental) com 24 meses de idade, confinadas por 56 dias, estudaram a substituição do milho 
pela mandioca e seus resíduos industriais e obtiveram PVA de $416,1 \mathrm{~kg}$.

Scheaffer et al. (2001) verificaram peso ao abate de 455,0 e 475,0 kg para novilhas aos dois anos vazias e prenhes, respectivamente. Observa-se, portanto, que o PVA é um parâmetro que varia conforme o manejo, a raça e a nutrição.

O PCQ médio global neste experimento foi de $171,1 \mathrm{~kg}$. Scheaffer et al. (2001) obtiveram peso de carcaça ao abate de 245,5 e 247,9 kg para novilhas aos dois anos de idade vazias e prenhes, respectivamente. O PCQ neste experimento foi inferior aos encontrados por Marques et al. (2001; $184,7 \mathrm{~kg}$ ). Este parâmetro está intimamente ligado ao PVA e também é influenciado pelos fatores supracitados.

O PAR médio obtido neste ensaio foi de 11,4 arrobas e sua importância está relacionada à forma de remuneração ao produtor. O valor mínimo varia de 10,0 a 12,0 arrobas entre as regiões no Brasil, de modo que valores inferiores resultam em desvalorização na comercialização de carcaças de fêmeas. Os valores obtidos neste ensaio (Tabela 2) foram superiores ao mínimo exigido e, portanto, atendem às exigências de mercado.

Como pode-se observar na Tabela 3 , não houve diferença entre os tratamentos para os comprimentos de carcaça (CC) e de perna (CP) e a espessura do coxão (EC) nas novilhas mestiças submetidas a anestro mecânico (CHU) ou cirúrgico (OVA), em comparação às do tratamento controle (VAZ).

OCC médio deste experimento foi de $113,8 \mathrm{~cm}$, superior ao descrito por Vaz et al. (2001), que observaram CC de $111,6 \mathrm{~cm}$ para fêmeas abatidas aos dois anos de idade. No entanto, Costa et al. (2002), em machos Red Angus terminados em confinamento e abatidos aos 12 e 13 meses $(340,0$ e $370,0 \mathrm{~kg}$ ), obtiveram CC de 113,8 e 116,6 cm, respectivamente, demonstrando que o peso e o porte, independentemente do sexo, são determinantes desta característica.

Tabela 3 - Comprimentos de carcaça (CC) e de perna (CP) e espessura do coxão (EC) de novilhas mestiças submetidas ao anestro mecânico ( $\mathrm{CHU}$ ) ou cirúrgico (OVA) em comparação às do tratamento controle (VAZ)

Table 3 - Carcass length (CL), hind limb length (HL) and cushion thickness (CT) of heifers submitted to mechanical (LEAD) or surgical anoestrous (OVAE) compared to control (CTRL)

\begin{tabular}{llcccc}
\hline $\begin{array}{l}\text { Parâmetro } \\
\text { Item }\end{array}$ & $\begin{array}{l}\mathrm{VAZ} \\
\text { CTRL }\end{array}$ & $\begin{array}{c}\text { CHU } \\
\text { LEAD }\end{array}$ & $\begin{array}{c}\text { OVA } \\
\text { OVAE }\end{array}$ & $\begin{array}{c}\text { Média } \\
\text { Mean }\end{array}$ & CV (\%)* \\
\hline $\begin{array}{l}\text { CC, cm } \\
\text { CL, cm }\end{array}$ & 114,0 & 114,1 & 113,4 & 113,8 & 2,9 \\
$\begin{array}{l}\text { CP, cm } \\
H L, c m\end{array}$ & 68,4 & 68,6 & 67,6 & 68,2 & 3,4 \\
$\begin{array}{l}\text { EC }, \mathrm{cm} \\
\text { CT, cm }\end{array}$ & 21,1 & 21,6 & 20,2 & 21,0 & 4,9
\end{tabular}

${ }^{*}$ Coeficiente de variação (Coefficient variation).
O CP médio dos três tratamentos foi de $68,2 \mathrm{~cm}$. Flores (1997) e Restle et al. (1997a) afirmaram que animais mestiços Nelore, dependendo da raça, apresentam maior comprimento de perna. O CP foi semelhante ao encontrado por Costa et al. (2002), que, em experimento com machos Red Angus terminados em confinamento e abatidos aos 14 e 15 meses de idade (400,0 e 430,0 kg), obtiveram CP de 64,4 e 71,2 cm, respectivamente, demonstrando que esta característica não foi influenciada pela condição reprodutiva.

A EC é um dos itens importantes na quantificação da musculosidade da carcaça. $\mathrm{O}$ valor médio encontrado neste trabalho $(21,0 \mathrm{~cm})$ foi inferior ao obtido por Restle et al. (2001a), em novilhas Charolesas e mestiças ( $3 / 4$ Charolesa $x$ $1 / 4$ Nelore) com três anos de idade (médio de $25,6 \mathrm{~cm}$ ). Vaz et al. (2002) em estudo com animais da raça Hereford, animais de porte semelhante ao deste experimento, terminados em confinamento aos dois anos de idade, encontraram EC de $22,3 \mathrm{~cm}$, confirmando que o porte e o peso ao abate interferem nos valores desta variável.

Os valores médios para área de olho-de-lombo (AOL), área de olho-de-lombo por $100 \mathrm{~kg}$ de carcaça (AOC) e espessura de gordura de cobertura (EGC) foram de $57,3 \mathrm{~cm}^{2}$, $33,9 \mathrm{~cm}^{2}$ e 4,0 mm, respectivamente, não havendo diferença entre os tratamentos (Tabela 4). No entanto, a EGC foi de 4,0; 4,4 e 3,5 mm para os tratamentos VAZ, OVA e CHU, com diferença de aproximadamente $0,5 \mathrm{~mm}$ entre os tratamentos. Todavia, não foi observada diferença, possivelmente pela heterogeneidade dos dados, confirmada pelo coeficiente de variação (22,6\%). Estas informações corroboram as de Zinn et al. (1989), que afirmam que a ovariectomia não afeta a deposição de gordura na carcaça.

A AOL é outro importante indicador da musculosidade da carcaça e aumenta conforme o peso da carcaça. Esperava-se

Tabela 4 - Área de olho-de-lombo (AOL), área de olho-de-lombo por $100 \mathrm{~kg}$ de carcaça (AOC) e espessura de gordura de cobertura (EGC) de novilhas mestiças submetidas ao anestro mecânico (CHU) ou cirúrgico (OVA), em comparação às do tratamento controle (VAZ), terminadas em confinamento

Table 4 - Longissimus dorsi area (LDA), longissimus dorsi area per 100 $\mathrm{kg}$ of carcass (LDA\%) and subcutaneous fat thickness (FAT) of the heifers submitted to mechanical (LEAD) or surgical anoestrous (OVAE) compared to control (CTRL)

\begin{tabular}{lccccc}
\hline $\begin{array}{l}\text { Parâmetro } \\
\text { Item }\end{array}$ & $\begin{array}{l}\mathrm{VAZ} \\
\text { CTRL }\end{array}$ & $\begin{array}{l}\text { CHU } \\
\text { LEAD }\end{array}$ & $\begin{array}{c}\text { OVA } \\
\text { OVAE }\end{array}$ & $\begin{array}{c}\text { Média } \\
\text { Mean }\end{array}$ & CV (\%)* \\
\hline $\begin{array}{l}\mathrm{AOL}, \mathrm{cm}^{2} \\
L D A, \mathrm{~cm}^{2}\end{array}$ & 57,6 & 58,9 & 55,5 & 57,3 & 12,1 \\
$\begin{array}{l}\mathrm{AOC} \%, \mathrm{~cm}^{2} \\
L D A \%, \mathrm{~cm}^{2}\end{array}$ & 32,9 & 34,5 & 34,1 & 33,9 & 14,8 \\
$\begin{array}{l}\mathrm{EGC}, \mathrm{mm} \\
\text { FAT, } \mathrm{mm}\end{array}$ & 4,0 & 4,4 & 3,5 & 4,0 & 22,6 \\
\hline
\end{tabular}

${ }^{*}$ Coeficiente de variação (Coefficient variation). 
que os animais do tratamento OVA apresentassem menor AOL - a ovariectomia reduz a deposição de proteína sem afetar a de gordura (Zinn et al., 1989) - e que os animais do tratamento $\mathrm{CHU}$, em razão do efeito anabolizante dos hormônios da reprodução, apresentassem maior AOL (Rumsey et al., 1999).

O valor médio encontrado neste trabalho $\left(57,3 \mathrm{~cm}^{2}\right)$ foi superior ao obtido por Vaz et al. (2002), que, em experimento com machos inteiros Hereford confinados e abatidos aos dois anos, encontraram AOL de $54,5 \mathrm{~cm}^{2}$. Esta característica é influenciada pelo sexo, a idade, a raça, o tamanho e o peso do animal, pois animais machos, mais velhos, grandes e pesados, normalmente, apresentam AOL maior.

A AOL média, quando ajustada para $100 \mathrm{~kg}$ de PV (AOC), foi de $33,9 \mathrm{~cm}^{2}$, superior à encontrada por Costa et al. (2002), que, em bovinos Red Angus machos com 12 a 15 meses de idade e peso de abate de 340,0 a $430,0 \mathrm{~kg}$, observaram decréscimo linear nesta relação, passando de 29,9 para $26,3 \mathrm{~cm}^{2}$, respectivamente.

A EGC $(4,0 \mathrm{~mm})$ foi superior à encontrada por Vaz et al. (1999), em experimento com machos Charolês e mestiços $3 / 4$ Charolês $\mathrm{x} 1 / 4$ Nelore com idade ao abate de dois anos (2,2 e $2,8 \mathrm{~mm}$, respectivamente). Esses resultados comprovam que animais de grande porte demoram mais tempo para depositar gordura. Essa característica é influenciada, entre outros fatores, pela maturidade fisiológica, pelo tamanho adulto do animal e pela densidade energética da dieta. Como o mercado exige valores de 3,0 a 6,0 mm, os valores médios deste trabalho $(4,0 \mathrm{~mm})$ estão dentro destes limites.

Tabela 5 - Porcentagens de músculo (PM), osso (PO) e gordura (PG) e relações músculo/osso e músculo + gordura/ osso em carcaças de novilhas mestiças submetidas ao anestro mecânico ( $\mathrm{CHU}$ ) ou cirúrgico (OVA), em comparação às do tratamento controle (VAZ), terminadas em confinamento

Table 5 - $\quad$ Muscle percentage (MP), bone percentage (BP), fat percentage $(F P)$, muscle/bone ratio and muscle + fat/bone ration in carcass of heifers submitted to mechanical (LEAD) or surgical anoestrous (OVAE) compared to control (CTRL)

\begin{tabular}{|c|c|c|c|c|c|}
\hline $\begin{array}{l}\text { Parâmetro } \\
\text { Item }\end{array}$ & $\begin{array}{l}\text { VAZ } \\
\text { CTRL }\end{array}$ & $\begin{array}{l}\text { CHU } \\
\text { LEAD }\end{array}$ & $\begin{array}{l}\text { OVA } \\
\text { OVAE }\end{array}$ & $\begin{array}{l}\text { Média } \\
\text { Mean }\end{array}$ & $\mathrm{CV}(\%)^{*}$ \\
\hline $\begin{array}{l}\mathrm{PM}, \% \\
M P, \%\end{array}$ & 60,9 & 63,8 & 63,0 & 62,6 & 4,6 \\
\hline $\begin{array}{l}\mathrm{PO}, \% \\
B P, \%\end{array}$ & 15,9 & 15,8 & 16,2 & 16,0 & 4,9 \\
\hline $\begin{array}{l}\mathrm{PG}, \% \\
F P, \%\end{array}$ & 23,5 & 20,6 & 20,9 & 21,7 & 15,8 \\
\hline $\begin{array}{l}\text { Relação músculo/osso } \\
\text { Muscle/bone ratio }\end{array}$ & 3,8 & 4,0 & 3,8 & 3,9 & 5,6 \\
\hline $\begin{array}{l}\text { Relação músculo }+ \\
\text { gordura/osso } \\
\text { Muscle + fat/bone ratio }\end{array}$ & 5,3 & 5,3 & 5,1 & 5,3 & 6,4 \\
\hline
\end{tabular}

${ }^{*}$ Coeficiente de variação (Coefficient variation).
Não houve diferença significativa entre os tratamentos para as porcentagens de músculo (PM), osso (PO) e gordura (PG) e para as relações músculo/gordura e músculo + gordura (porção comestível)/osso (Tabela 5), o que indica que a condição reprodutiva não interferiu nas proporções e na relação entre os tecidos.

Segundo Carballo et al. (2000), as proporções médias de cada um dos componentes da carcaça são muito variáveis, oscilando entre 48,0 e $82,0 \%$ para carne, entre 0,5 e $35,0 \%$ para gordura e entre 11,0 e 35,0\% para osso. À medida que o período de terminação avança, a composição do ganho de peso é alterada, de modo que o crescimento inicial, predominantemente muscular, dá lugar à maior retenção de energia na forma de gordura. Esse processo é influenciado principalmente pelo nível nutricional e ocorre de forma mais acentuada para a relação gordura:proteína (Di Marco, 1998).

Neste trabalho, esperava-se que o tratamento CHU apresentasse maior PM e menor PG e que o tratamento OVA tivesse tendência oposta, em virtude da atividade hormonal (Zinn et al., 1989; Rumsey et al., 1999), o que, possivelmente, se deve à ausência de efeito anabolizante das esferas de chumbo.

A PM média de $62,6 \%$ foi semelhante à encontrada por Costa et al. (2002) em machos Red Angus abatidos com diferentes pesos (62,1\%). Da mesma forma, Vaz et al. (2002) encontraram valores de PM semelhantes $(63,4 \%)$ em machos da raça Hereford abatidos aos dois anos de idade.

A PO média de $16,0 \%$ foi superior à encontrada por Costa et al. (2002), em machos Red Angus abatidos com diferentes pesos $(14,1 \%)$, não sendo observada alteração nesta variável com o aumento do peso dos animais. Vaz et al. (2002) também relataram PO de 15,2\%, inferior à deste trabalho, embora machos Hereford, abatidos aos dois anos.

A PG média foi de $21,7 \%$, semelhante à descrita por Vaz et al. (2002), de 21,1\%. No entanto, foi inferior à encontrada por Costa et al. (2002), em machos Red Angus abatidos com diferentes pesos $(24,3 \%)$

Segundo Berg \& Buterfield (1976), citados por Costa et al. (2002), uma carcaça superior, para qualquer mercado, deve ter quantidade máxima de músculo, mínima de osso e ótima de gordura, que varia conforme a preferência do consumidor. Neste trabalho, a PM foi superior a 60,0\%, a PG ficou em $21,7 \%$ e a EGC foi de $4,0 \mathrm{~mm}$, apresentando, portanto, padrões compatíveis com as exigências do mercado interno.

A relação músculo/osso foi de 3,9 e não variou entre os tratamentos. Este valor foi inferior aos reportados por Costa et al. (2002), de 4,4, e Vaz et al. (2002), em machos Hereford.

A relação músculo+gordura/osso, ou seja, a porção comestível/osso, foi de 5,3, inferior aos valores registrados 
Tabela 6 - Perdas por descongelamento (PD) e cocção (PC), perdas da carne congelada após a cocção (CO), maciez, suculência e palatabilidade da carne de novilhas mestiças submetidas ao anestro, mecânico (CHU) ou cirúrgico (OVA), em comparação às do tratamento controle (VAZ), terminadas em confinamento

Table 6 - Thawing $(L T)$, cooking ( $L C)$, freezing to cooking losses ( $L T C)$, tenderness, juiciness, and flavor of meat of heifers submitted to mechanical (LEAD) or surgical anoestrous (OVAE) compared to control (CTRL)

\begin{tabular}{|c|c|c|c|c|c|}
\hline $\begin{array}{l}\text { Parâmetro } \\
\text { Item }\end{array}$ & $\begin{array}{l}\mathrm{VAZ} \\
\text { CTRL }\end{array}$ & $\begin{array}{l}\text { CHU } \\
\text { LEAD }\end{array}$ & $\begin{array}{l}\text { OVA } \\
\text { OVAE }\end{array}$ & $\begin{array}{l}\text { Média } \\
\text { Mean }\end{array}$ & $\mathrm{CV}(\%)^{*}$ \\
\hline $\begin{array}{l}\mathrm{PD}, \% \\
L T, \%\end{array}$ & $9,8^{\mathrm{b}}$ & $9,2^{\mathrm{ab}}$ & $7,0^{\mathrm{a}}$ & 8,6 & 1,8 \\
\hline $\begin{array}{l}\mathrm{PC}, \% \\
L C, \%\end{array}$ & 25,9 & 24,0 & 22,9 & 24,2 & 4,5 \\
\hline $\begin{array}{l}\text { CO, \% } \\
\text { LTC, \% }\end{array}$ & 33,2 & 31,0 & 28,3 & 30,8 & 4,6 \\
\hline $\begin{array}{l}\text { Maciez, pontos } \\
\text { Tenderness, score }\end{array}$ & 7,3 & 7,0 & 6,7 & 7,0 & 10,2 \\
\hline $\begin{array}{l}\text { Suculência, pontos } \\
\text { Juiciness, score }\end{array}$ & 6,9 & 6,5 & 6,3 & 6,5 & 8,3 \\
\hline $\begin{array}{l}\text { Palatabilidade, pontos } \\
\text { Flavor, score }\end{array}$ & 6,8 & 6,4 & 6,5 & 6,5 & 8,6 \\
\hline
\end{tabular}

Médias, na linha, seguidas de letras diferentes são distintas $(P<0,05)$ pelo teste Tukey.

Means, in a row, followed by different letters are different $(P<0.05)$ by Tukey test. ${ }^{*}$ Coeficiente de variação (Coefficient variation).

por Costa et al. (2002), de 6,1, e Vaz et al. (2002), de 5,6 (posição intermediária).

Como pode ser observado na Tabela 6, os valores obtidos para perdas por descongelamento (PD) e cocção (PC) e perdas da carne congelada após cocção (CO), maciez, suculência e palatabilidade da carne não diferiram entre os tratamentos.

Por outro lado, as $\mathrm{PD}$ foram maiores $(\mathrm{P}<0,05)$ para as novilhas do tratamento VAZ ( $9,8 \%$ vs $7,0 \%$ - OVA), ficando o tratamento CHU (9,2\%) em posição intermediária. Este valor inferior para as novilhas do tratamento OVA não era esperado, pois esses animais apresentaram menor porcentagem de gordura na carcaça e menor espessura de gordura de cobertura (20,9\% e $3,5 \mathrm{~mm}$, respectivamente), quando comparadas às do tratamento VAZ, o que, teoricamente, poderia proporcionar maiores perdas no processo de descongelamento, visto que a gordura, além de melhorar as características sensoriais, mantém a umidade da carne.

As PD foram de $8,6 \%$, superior ao dobro do encontrado por Vaz et al. (2002), de 3,9\%, em novilhos Hereford nãocastrados abatidos aos 24 meses de idade. No entanto, as PC (31,5\%) observadas por estes autores foram superiores às deste trabalho $(24,2 \%)$, resultando, portanto, em $\mathrm{CO}$ maior $(35,5 \%)$ que a obtida neste experimento $(30,8 \%)$.

As PC, a suculência e a palatabilidade foram semelhantes entre os tratamentos. A gordura da carne também influencia a suculência, pois a distribuição uniforme de lipídios no músculo favorece a palatabilidade da carne e serve como barreira contra a perda de suco muscular durante o cozimento (Forrest et al., 1979, citados por Vaz et al. 2002). Portanto, a palatabilidade está correlacionada à maciez e suculência da carne.

Os valores encontrados para maciez, suculência e palatabilidade foram, respectivamente, de 7,$0 ; 6,5$ e 6,5 pontos, caracterizando a carne como macia, levemente acima da média a suculenta e levemente acima da média a saborosa, respectivamente. O valor para maciez foi superior ao descrito por Restle et al. (1997b), que, em animais mestiços ( $1 / 2$ Hereford versus $1 / 2$ Nelore) abatidos aos 24 meses, registraram 5,1 pontos. Costa et al. (2002), em machos inteiros Red Angus abatidos com diferentes pesos, encontraram maciez de 6,5 e 6,3 pontos para os animais com pesos de abates de 340 e $370 \mathrm{~kg}$, respectivamente. A média para suculência foi maior que a encontrada por Restle et al. (2001a), de 5,7 pontos, em fêmeas ( $3 / 4$ Charolesa $\mathrm{x} 1 / 4$ Nelore) abatidas aos três anos de idade.

A média para palatabilidade foi semelhante à reportada por Costa et al. (2002), em machos inteiros Red Angus abatidos com diferentes pesos (6,3 e 6,1 pontos para 340 e $370 \mathrm{~kg}$ ). Esses autores destacaram a associação positiva entre palatabilidade e marmoreio e extrato etéreo, indicando que a gordura contém substâncias flavorizantes agradáveis ao paladar. Do mesmo modo, observaram que a maciez da carne, assim como a suculência, está associada à palatabilidade, indicando que carnes mais macias são mais saborosas.

A cor (COR), a textura (TXT) e o marmoreio (MAR) não diferiram com a alteração da condição reprodutiva (Tabela 7), sendo observados valores de 4,0; 4,4 e 3,7 pontos, que correspondem a cor vermelha, a textura fina a muito fina e a marmoreio leve menos a traços mais. A coloração da carne ( 4,0 pontos) foi superior à observada por Restle et al. (1997b), em animais Hereford puros e mestiços com Nelore (2,7 e 2,6 pontos, respectivamente).

Da mesma forma, foi superior ao valor encontrado por Restle et al. (2001a), em fêmeas mestiças ( $3 / 4$ Charolesa X $1 / 4$ Nelore, 3,1 pontos), caracterizada por vermelha levemente escura. No entanto, Restle et al. (2001b), trabalhando com vacas mestiças em pastagem, sob suplementação alimentar, obtiveram coloração vermelha a vermelha intensa, com valores superiores $(4,5$ pontos $)$ aos encontrados neste experimento.

A textura da carne ( 4,4 pontos) foi superior à descrita por Vaz et al. (2002), fina (4,2 pontos), em estudo com novilhos Hereford abatidos aos dois anos de idade. A pontuação também foi maior que a de 4,0 pontos, reportada por Costa et al. (2002) para caracterizar carne com textura fina. 
Tabela 7 - Cor (COR), textura (TXT) e marmoreio (MAR) de carcaças de novilhas mestiças submetidas ao anestro mecânico (CHU) ou cirúrgico (OVA), em comparação às do tratamento controle (VAZ), terminadas em confinamento

Table 7 - Color (COL), texture (TEX) and marbling (MAR) of carcass of heifers submitted to mechanical (LEAD) or surgical anoestrous (OVA) compared to control (CTRL)

\begin{tabular}{lccccc}
\hline $\begin{array}{l}\text { Parâmetro } \\
\text { Parameter }\end{array}$ & $\begin{array}{l}\mathrm{VAZ} \\
\text { CTRL }\end{array}$ & $\begin{array}{c}\text { CHU } \\
\text { LEAD }\end{array}$ & $\begin{array}{c}\text { OVA } \\
\text { OVAE }\end{array}$ & $\begin{array}{c}\text { Média } \\
\text { Mean }\end{array}$ & CV (\%)* \\
\hline $\begin{array}{l}\text { COR, pontos } \\
\text { COL, score }\end{array}$ & 4,0 & 4,0 & 4,0 & 4,0 & 12,9 \\
$\begin{array}{l}\text { TXT, pontos } \\
\text { TEX, score }\end{array}$ & 4,6 & 4,5 & 4,2 & 4,4 & 10,7 \\
$\begin{array}{l}\text { MAR, pontos } \\
\text { MAR, score }\end{array}$ & 3,8 & 3,2 & 4,2 & 3,7 & 31,7 \\
\end{tabular}

*Coeficiente de variação (Coefficient variation).

O marmoreio da carne ou da gordura entremeada é a última gordura a ser depositada na fase final de acabamento da carcaça, após ou no final do período de crescimento, e depende da raça e do nível energético da dieta (Felício, 1993). $\mathrm{O}$ MAR (3,7 pontos) foi inferior ao encontrado por Vaz et al. (2002), leve menos e leve médio (4,3 pontos), na carne de novilhos Hereford abatidos aos dois anos de idade. Todavia, foi superior ao observado por Restle et al. (2001a), leve médio, em fêmeas mestiças $3 / 4$ Charolesa x $1 / 4$ Nelore $(5,0$ pontos).

Constam na Tabela 8 os dados referentes aos teores de umidade (UMI), CIN, PB, extrato etéreo total (EET) e colesterol (COL) verificados nos animais dos tratamentos VAZ, CHU e OVA. Não houve diferença significativa para as características CIN (1,1\%), PB (21,8\%), EET (2,9\%) e COL $(49,6 \mathrm{mg} / 100 \mathrm{~g})$ do músculo Longissimus dorsi.

Todavia, a UMI foi maior para o tratamento OVA (75,1\%), embora semelhante a CHU (73,5\%) e VAZ (74,2\%). Possivelmente, essas diferenças estejam relacionadas a problemas na estocagem e manipulação das amostras, o que pode ter causado nível de desidratação diferente entre as amostras dos diferentes tratamentos, pois os fatores que poderiam influenciar a capacidade de retenção de água (CRA), como gordura (Ciria \& Asenjo, 2000) e idade (Di Marco, 1998), não foram diferentes entre os tratamentos, pois os animais apresentavam idade, porcentagem de gordura da carcaça e espessura de gordura subcutânea semelhantes.

A UMI média (74,3\%) foi superior (9,5 e 9,4\%) aos valores encontrados por Silva et al. (2002), que estudaram a influência de fontes protéicas e energéticas nas características químicas do músculo Longissimus dorsi de novilhas mestiças $1 / 2$ Nelore $\mathrm{x} 1 / 2$ Limousin e $1 / 2$ Nelore $\mathrm{x} 1 / 2$ Simental, respectivamente, com idade de abate e alimentação semelhantes a este experimento. $\mathrm{O}$ valor médio também
Tabela 8 - Percentuais de UMI, CIN, PB, EET e COL, em mg/100g de músculo Longissimus dorsi, sem gordura de cobertura, de novilhas mestiças terminadas em confinamento

Table 8 - $\quad$ Percentag of moisture (MOI), ash, crude protein (CP), total fat (TF) and cholesterol concentration (CHO), in $\mathrm{mg} / 100 \mathrm{~g}$, in Longissimus dorsi, free of fat cover layer, of heifers in feedlot

\begin{tabular}{|c|c|c|c|c|c|}
\hline $\begin{array}{l}\text { Parâmetro } \\
\text { Parameter }\end{array}$ & $\begin{array}{l}\mathrm{VAZ}^{1} \\
\text { CTRL }^{1}\end{array}$ & $\begin{array}{l}\mathrm{CHU}^{2} \\
L E A D^{2}\end{array}$ & $\begin{array}{l}\mathrm{OVA}^{3} \\
\text { OVAE }\end{array}$ & $\begin{array}{l}\text { Média } \\
\text { Mean }\end{array}$ & $\mathrm{CV}(\%)^{*}$ \\
\hline $\begin{array}{l}\text { UMI (\%) } \\
\text { MOI (\%) }\end{array}$ & $74,2^{\mathrm{ab}}$ & $73,5^{b}$ & $75,1^{\mathrm{a}}$ & 74,3 & 1,2 \\
\hline $\begin{array}{l}\text { CIN (\%) } \\
A S H(\%)\end{array}$ & 1,0 & 1,1 & 1,1 & 1,1 & 5,9 \\
\hline $\begin{array}{l}\mathrm{PBC}(\%) \\
C P(\%)\end{array}$ & 21,8 & 22,3 & 21,3 & 21,8 & 6,0 \\
\hline $\begin{array}{l}\text { EET }(\%) \\
\text { TF (\%) }\end{array}$ & 2,9 & 3,1 & 2,6 & 2,9 & 38,9 \\
\hline $\begin{array}{l}\text { COL }(\mathrm{mg} / 100 \mathrm{~g}) \\
\text { CHO }(\mathrm{mg} / 100 \mathrm{~g})\end{array}$ & 51,4 & 48,1 & 49,3 & 49,6 & 6,5 \\
\hline
\end{tabular}

${ }^{1} \mathrm{VAZ}$ - tratamento controle, ${ }^{2} \mathrm{CHU}$ - novilhas com chumbo no útero, ${ }^{3} \mathrm{OVA}$ - novilhas ovariectomizadas

Médias na mesma linha seguidas de letras diferente são distintas $(0,05)$ pelo teste Tukey.

${ }^{1} C T R L$ - control heifers; ${ }^{2} L E A D$ - lead spheres in uterine corn; ${ }^{3} O V A E$ - ovariectomized. Means, in a row, followed by different letters are different $(P<0,05)$ by Tukey test. ${ }^{*}$ Coeficiente de variação (Coefficient variation).

foi superior aos obtidos por Oliván et al. (2000), em sete raças de bovinos da Espanha (74,3\%), e aos encontrados por Abrahão et al. (2005), 73,8\%, em tourinhos jovens de diferentes grupos genéticos alimentados com silagem de sorgo, farelo de soja e níveis de substituição do milho por massa de fecularia úmida. Entretanto, estes valores foram semelhantes aos verificados por Moreira et al. (2003), de 74,3 e 75,3\%, respectivamente, em machos Nelore e mestiços terminados em pastagens de milheto e estrela-roxa.

Os teores de CIN contidos na carne possuem funções biológicas importantes, pois são constituintes de hormônios, enzimas, entre outros. Segundo Pardi et al. (2001), aproximadamente 3,5\% do peso corporal é de natureza inorgânica, do qual 80 a $85 \%$ encontra-se nos ossos e dentes, sobrando cerca de um ponto percentual para os tecidos moles. O teor de CIN $(1,1 \%)$ foi semelhante ao encontrado por Takeda (2002), 1,0\%, no Longissimus dorsi, sem gordura de cobertura, de animais em condições semelhantes às deste trabalho. Também foi semelhante aos encontrados por Silva et al. (2001), 1\%, em novilhas (1/2 Nelore e 1/2 Angus) confinadas, alimentadas com dieta contendo polpa cítrica, e por (Moreira et al., 2003), de $1 \%$, em machos Nelore e mestiços terminados em pastagens. Esses dados comprovam que os valores de CIN variam pouco, independentemente do tratamento.

As proteínas integram, sobretudo, os tecidos musculares e conjuntivos. Sua disponibilidade em aminoácidos essenciais e suas características de digestibilidade alta- 
mente favoráveis lhe conferem elevado valor biológico (Pardi et al., 2001).

Os teores de PB $(21,8 \%)$ foram superiores ao encontrado por Abrahão et al. (2005), 19,1\%, em tourinhos jovens de diferentes grupos genéticos alimentados com silagem de sorgo e farelo de soja, com substituição parcial do milho por massa de fecularia úmida. Porém, foi inferior aos valores relatados por Silva et al. (2002), que obtiveram 23,2 e $22,5 \%$, ao estudarem influência de fontes protéicas e energéticas nas características químicas do Longissimus dorsi de novilhas mestiças $1 / 2$ Nelore x $1 / 2$ Limousin e $1 / 2$ Nelore x $1 / 2$ Simental, com idade de abate semelhante à deste experimento. Esses mesmos autores, avaliando as características químicas do Longissimus dorsi de novilhas mestiças $1 / 2$ Nelore x $1 / 2$ Simental, com idade de abate semelhante, alimentadas com diferentes fontes energéticas, obtiveram valor de $23,2 \%$, superior aos deste trabalho.

As gorduras são o componente mais variável da carne e sua proporção oscila conforme a espécie, a raça, o sexo, o manejo, a alimentação, a região anatômica, a idade e o clima. A variabilidade do percentual da gordura influencia na proporção de proteína e demais constituintes da carne (Felício, 1998; Pardi et al., 2001).

A American Heart Association (AHA) recomenda o consumo de carne com nível máximo de gordura intramuscular (marmoreio) de 7,3\%. Todavia, tem-se demonstrado que carne com menos de 3,0\% de gordura não é bem aceita por painéis de avaliadores. Por isso, propõe-se que a gordura intramuscular fique entre 3,0 e 7,3\% (Di Marco, 1998).

O EET médio (2,9\%) ficou próximo aos valores mínimos recomendados pela AHA. Todavia, quando se observa a tendência de mercado, que busca carne com baixos níveis de gordura, esta baixa porcentagem de gordura intramuscular poderia representar uma vantagem. No entanto, esses valores foram inferiores aos encontrados em tourinhos jovens (1/2 Nelore e 1/2 Angus) confinados alimentados com dietas contendo polpa cítrica (3,9\% - Silva et al., 2001). Por outro lado, foram superiores aos encontrados por Silva et al. (2002), de 1,3 e 1,6\%. Observa-se que o teor de EET é bastante variável, o que se deve, entre outros fatores, à raça e ao grau de acabamento da carcaça, posto que animais terminados com maior acabamento de carcaça apresentam maior proporção de gordura intramuscular, uma das últimas a serem depositadas (Di Marco, 1998), encontrada quando se analisa o Longissimus dorsi sem a gordura de cobertura.

O colesterol, quando consumido em excesso, associado a desequilíbrio hormonal, estresse, entre outros fatores pré-condicionantes, está relacionado ao aparecimento de doenças, como insuficiência cardíaca e cálculos biliares.
Metade do colesterol do organismo origina-se da produção endógena e a outra parte, dos alimentos ingeridos (Lehninger et al., 2000) e, considerando que sua excreção é difícil, o conhecimento dos teores de colesterol na dieta é fundamental (Costa et al., 2002).

O COL não diferiu significativamente entre os tratamentos e o valor médio para os três tratamentos foi de $49,6 \mathrm{mg} / 100 \mathrm{~g}$, superior aos $42,4 \mathrm{mg} / 100 \mathrm{~g}$ encontrados por Silva (2000). Da mesma forma, foi superior ao descrito por Moreira et al. (2003), que obtiveram 37,4 mg/100 g em machos terminados em pastagens, provavelmente em razão do maior aporte energético da dieta utilizada neste experimento. Esses resultados comprovam a interferência direta da dieta sobre os teores de colesterol, pois animais em pastagens ou alimentados com diferentes fontes energéticas no concentrado apresentam distintos valores de colesterol em seus tecidos.

\section{Conclusões}

A supressão do cio não alterou as características físicas da carcaça e a qualidade da carne.

A composição química, ou seja, os valores de proteína, cinzas, extrato etéreo total e colesterol, não foi afetada pelo ciclo estral.

\section{Implicações}

Considerando os teores de colesterol e extrato etéreo e os recomendados para consumo diário pela Associação de Saúde Americana (AHA), pode-se consumir até $600 \mathrm{~g}$ de contra-filé, sem gordura de cobertura, por dia.

\section{Literatura Citada}

ABRAHÃO, J.J.S.; PRADO, I.N., PEROTTO, D. et al Características de carcaças e da carne de tourinhos submetidos a dietas com diferentes níveis de substituição do milho por resíduo úmido da extração da fécula de mandioca características de carcaças e da carne de tourinhos. Revista Brasileira de Zootecnia, v.34, n.5, p.1640-1650, 2005.

AL-HASANI, S.M.; HLAVAC, J.; CARPENTER, M.W. Rapid determination of cholesterol in single and multi-componen prepared foods. Journal of Association of Official Analytical Chemists International, v.76, p.902-906, 1993.

ANUAlPEC. Anuário da Pecuária Brasileira. FNP Consultoria: São Paulo: 2003, 400p.

ASSOCIATION OF OFFICIAL ANALITICAL CHEMISTS - AOAC. Official methods of analysis. 14.ed. Washington, D.C.: 1980 $1094 \mathrm{p}$.

BOBBIO, F.O.; BOBBIO, P.A. Introdução à química dos alimentos. 2.ed. $1^{\text {a }}$ reimpressão, São Paulo: Varela, 1995. $151 \mathrm{p}$.

CARBALlO, J.A.; MONSERRAT, L.; SÁNCHEZ, L. Composición de la carnal bovina. In: CAÑEQUE, V.; SAÑUDO, C. (Eds.) Metodología para el estudio de la calidad de la carnal y de la carne en rumiantes. 1.ed. Madri: INIA, 2000. p.106-123. 
CIRIA, J.; ASENJO, B. Factores a considerar en el presacrificio y postsacrificio. In: CAÑEQUE, V.; SAÑUDO, C. (Eds.) Metodología para el estudio de la calidad de la carnal y de la carne en rumiantes. 1.ed. Madri: INIA, 2000. p.20-45.

COSTA, E.C.; RESTLE, J.; VAZ, F.N. et al. Características da carcaça de novilhos Red Angus superprecoces abatidos com diferentes pesos. Revista Brasileira de Zootecnia, v.31, n.1, p.119-128, 2002

CROWE, M.A.; ENRIGHT, W.J.; SWIFT, P. et al. Growth and estrous behavior of heifers actively immunized against prostaglandine $F_{2 a}$. Journal of Animal Science, n.73, p.345-352, 1995.

DI MARCO, O.N. Crecimiento de vacunos para carne. 1.ed. Buenos Aires: Oscar N. DiMarco. 1998. 246p.

FELÍCIO, P.E. Fatores ante e post-mortem que afetam a qualidade da carne vermelha. In: REUNIÃO ANUAL DA SOCIEDADE BRASILEIRA DE ZOOTECNIA, 30., 1993, Rio de Janeiro. Anais... Viçosa, MG: Sociedade Brasileira de Zootecnia, 1993. p.43-52.

FLORES, J.L. Desempenho em confinamento de terneiros de diferentes grupos genéticos na fase do desmame ao abate aos 14 meses. Santa Maria: Universidade Federal de Santa Maria, 1997. 136p. Dissertação (Mestrado em Zootecnia) Universidade Federal de Santa Maria, 1997.

HANKINS, O.G.; HOWE, P.E. Estimation of the composition of beef carcasses and cuts. Washington: Agriculture Department, 1946. 20p. (Technical Bulletin, 926).

KUTSUNUGI, E. Níveis plasmáticos de metabólitos e hormônios em novilhas mestiças terminadas em confinamento em função da gestação, ovariectomia ou esferas de chumbo implantadas no útero. Maringá: Universidade Estadual de Maringá, 2004. 25p. Monografia (Graduação em Zootecnia) Universidade Estadual de Maringá, 2004.

JIMÉNEZ-COLMENERO, F.; CARBALLO, J.; COFRADES, J. Healthier meat and meat products: their role as functional foods. Meat Science, v.59, n.1, p.5-13, 2001.

LEHNINGER, A.L.; NELSON, D.L.; COX, M.M. The biosynthesis of lipids. In: LEHNINGER, A.L. (Ed.). Principles of biochemistry. 3.ed. New York: Worth Publishers, 2000. p.780-817.

MARQUES, J.A.; PRADO, N.I.; ZEOULA, L.M. et al. Avaliação da mandioca e seus resíduos Industriais em substituição ao milho no desempenho de novilhas de corte. Revista Brasileira de Zootecnia, v.29, n.5, p.1528-1536, 2000

MARQUES, J.A.; PRADO, I.N.; NASCIMENTO, W.G. et al. Avaliação do desempenho de novilhas mestiças em diferentes condições reprodutivas confinadas. In: REUNIÃO ANUAL DA SOCIEDADE BRASILEIRA DE ZOOTECNIA, 38., 2001, Piracicaba. Anais... Piracicaba: Sociedade Brasileira de Zootecnia, 2001. (CD-ROM)

MOLETTA, J.L.; RESTLE, J. Influência do grupo genético sobre características qualitativas da carne de novilhos. Revista Brasileira de Zootecnia, v.25, n.5, p.866-875, 1996.

MOLETTA, J.L.; RESTLE, J. Influência do grupo genético sobre características qualitativas da carne de novilhas. Revista da Sociedade Brasileira de Zootecnia, v.25, n.5, p.866-875, 1996 .

MOREIRA, F.B.; SOUZA, N.E.; MATSUSHITA, M. et al. Evaluation of carcass characteristics and meat chemical composition of Bos indicus and Bos indicus x Bos taurus crossbred steers finished in pasture systems. Brazilian Archives of Biology and Technology v.46, n.4, p.609-616, 2003

MÜLLER, L. Normas para avaliação de carcaça e concurso de carcaças de novilhos. 1.ed. Santa Maria: Universidade Federal de Santa Maria, 1980. 31p

OLIVÁN, M.; MOCHA, M.J.; MARTINEZ, M.J. et al. Análisis químico de la carne. In: CAÑEQUE, V.; SAÑUDO, C. (Eds.) Metodología para el estudio de la calidad de la carnal y de la carne en rumiantes. 1.ed. Madri: INIA, 2000. p.181203.

PARDI, M.C.; SANTOS, I.F.; SOUZA, E.R. et al. Ciência, higiene e tecnologia da carne. 2.ed. Goiânia: Universidade Federal de Santa Goiás, 2001. 623p.
PENSEL, N. The future of red meat in human diets. Nutrition Abstracts and Reviews, (Series A), v.68, n.1, p.1-4, 1998.

PRADO, I.N.; MARTINS, A.S.; ALCALDE, C.R. et al. Desempenho de novilhas alimentadas com rações contendo milho ou casca de mandioca como fonte energética e farelo de algodão ou levedura como fonte protéica. Revista Brasileira de Zootecnia, v.29, n.1, p.278-287, 2000

RESTLE, J.; FLORES, J.L.C.; VAZ, F.N. et al. Desempenho em confinamento, do desmame ao abate aos quatorze meses, de bovinos inteiros ou castrados, produzidos por vacas de dois anos. Ciência Rural, v.27, n.4, p.651-655, 1997a.

RESTLE, J.; KEPLIN, L.A.S.; VAZ, F.N. et al. Características quantitativas da carcaça de novilhos Chorelês confinados e abatidos com diferentes pesos. Pesquisa Agropecuária Brasileira, v.32, n.8, p.851-856, 1997b.

RESTLE, J.; BRONDANI, I.L.; BERNARDES, R.A.C. O novilho superprecoce.In: RESTLE, J. (Ed.) Confinamento, pastagens e suplementação para a produção de bovinos de corte. Santa Maria: Universidade Federal de Santa Maria, 1999. p.866-875.

RESTLE, J.; CERDÓTES, L.; VAZ, F.N. et al. Características de carcaça e da carne de novilhas Charolês e 3/4 Clarolês 1/4 Nelore terminadas em confinamento. Revista Brasileira de Zootecnia, v.30, n.3, p.1065-1075, 2001a (supl. 1).

RESTLE, J.; VAZ, F.N.; OLIVEIRA, A.N. et al. Desempenho e características de carcaça de vacas de diferentes grupos genéticos em pastagem cultivada com suplementação energética. Revista Brasileira de Zootecnia, v.30, n.6, p.1813-1823, 2001b.

RUMSEY, T.S.; ELSSASER, T.H.; KAHL, S. Performance and digestibilities of beef cattle fed diets suplemented with either soybean meal or roasted soybeans and implanted with synovex. Journal of Animal Science, v.77, p.1631-1637, 1999.

SCHEAFFER, A.N.; CATON, J.S.; BAUER, M.L. et al. Influence of pregnancy on body weight, ruminal characteristics and visceral organ mass in beef heifers. Journal of Animal Science, n.79, p.2481-2490, 2001

SILVA, R.C., PRADO, I.N.; MATSUSHITA, M. et al. effects of substitution of corn by pulp citrous pellets on muscle fatty acid composition of finished heifers. Associação Brasileira de Química, v.50, n.4, p.175-181, 2001.

SILVA, R.G.; PRADO, I.N.; MATSUSHITA, M. et al. Dietary effects on muscle fatty acid composition of finished heifers. Pesquisa Agropecuária Brasileira, v.37, n.1, p.95-101, 2002.

TAKEDA, H.H. Análise físico-química e perfil em ácidos graxos do músculo Longissimus dorsi de novilhas mestiças com implante de chumbo no útero, ovariectomizadas e testemunhas. Maringá: Universidade Estadual de Maringá, 2002, 86p. Dissertação (Mestrado em Química) - Universidade Estadual de Maringá, 2002

UNIVERSIDADE FEDERAL DE VIÇOSA - UFV. SAEG - Sistema de Análises Estatísticas e Genéticas. Versão 7.1. Viçosa, MG: 1997. 150p. (Manual do usuário)

VAZ, F.N.; ROSO, C.; VAZ, R.Z. Gerenciamento visando a eficiência econômica da pecuária de corte. In: RESTLE, J. (Ed.) Confinamento, pastagens e suplementação para a produção de bovinos de corte. Santa Maria: Universidade Federal de Santa Maria, 1999. p.233-259.

VAZ, F.N.; RESTLE, J.; VAZ, R.Z. et al. Efeito de raças e heterose na composição física da carcaça e qualidade da carne de novilhos da primeira geração de cruzamento entre Charolês e Nelore. Revista Brasileira de Zootecnia, v.31, n.1, p.376-386, 2001 (supl.).

VAZ, F.N.; RESTLE, J.; QUADROS, A.R.B.; et al. Características de carcaça e da carne de novilhos e vacas de descarte Hereford, terminadas em confinamento. Revista Brasileira de Zootecnia, v.31, n.3, p.1501-1510, 2002 (supl.)

ZINN, S.A.; CHAPIN, L.T.; ENRIGHT, W.J. et al. Growth, carcass composition and serum hormone responses to photoperiod and ovariectomy in heifers. Animal Production, v.49, p.365, 1989.

Recebido: 29/06/04 Aprovado: 22/02/06 